\title{
EMERGÊNCIA E CRESCIMENTO INICIAL DE PLANTAS DE Parkinsonia aculeata L. (FABACEAE) EM SUBSTRATO SALINO ${ }^{1}$
}

Francisco Thiago Coelho Bezerra², Leonaldo Alves de Andrade ${ }^{3}$, Lourival Ferreira Cavalcante ${ }^{3}$, Walter Esfrain Pereira ${ }^{3}$ e Marlene Alexandrina Ferreira Bezerra ${ }^{4}$

\begin{abstract}
RESUMO - A espécie Parkinsonia aculeata L. ocorre em zonas áridas, semiáridas e subúmidas, encontrando-se dispersa em várias regiões do planeta, onde é empregada em diferentes usos. Porém, em determinados ambientes, como caatinga e ecossistemas associados do Nordeste brasileiro, a espécie apresenta caráter invasor. Dessa forma, um experimento foi desenvolvido em abrigo telado para avaliar os efeitos da salinidade no comportamento germinativo e vegetativo de plantas de Parkinsonia aculeata. Inicialmente, o material de um Argissolo VermelhoAmarelo foi irrigado com água salina $\left(0,2 ; 1,5 ; 3,0 ; 4,5\right.$; e 6,0 dS m$\left.{ }^{-1}\right)$. Em seguida, foram acondicionados $16 \mathrm{~kg}$ de cada substrato em vasos plásticos com capacidade para $21 \mathrm{~L}$, e os tratamentos foram arranjados em blocos casualizados com nove repetições. Após a emergência, 10 dias após a semeadura, realizou-se o desbaste, deixando quatro plântulas por vaso. As variáveis avaliadas foram: emergência, índice de velocidade de emergência, concentrações das clorofilas a, b e total, diâmetro do caule no nível do solo, altura e número de folhas, 69 dias após a semeadura. $\mathrm{O}$ aumento da salinidade no solo de não salino (CEes $<2 \mathrm{dS} \mathrm{m}^{-1}$ ) para ligeiramente salino ( $4 \mathrm{dS} \mathrm{m}^{-1}>$ CEes $\left.>2 \mathrm{dS} \mathrm{m}^{-1}\right)$ e moderadamente salino $\left(8 \mathrm{dS} \mathrm{m}^{-1}>\right.$ CEes $\left.>4 \mathrm{dS} \mathrm{m}^{-1}\right)$ estimulou a emergência, o crescimento inicial e a produção de clorofila nas plantas de Parkinsonia aculeata, ao contrário do que ocorre com a grande maioria das espécies. Em parte, isso explica o sucesso de sua proliferação em determinados sítios da caatinga.
\end{abstract}

Palavras-chave: Turco; Caatinga; Invasão biológica.

\section{EMERGENCE AND INITIAL GROWTH OF Parkinsonia aculeata L. PLANTS (FABACEAE) UNDER SALINE SUBSTRATE}

\begin{abstract}
The species Parkinsonia aculeata L. occurs in arid, semiarid and subhumid zones around the world, where it is used in different proposes. However, in certain environments, as for example, caatinga and associated ecosystems in the Northeastern Brazil, the species has an invader behavior. Thus, an experiment was conducted under greenhouse conditions to evaluate the effects of salinity on the germination behavior and vegetative growth of Parkinsonia aculeata. Initially, the material of an Ultisol was irrigated with saline water

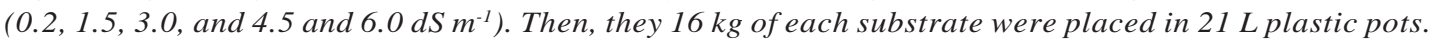
The treatments were arranged in randomized blocks with nine replicates. After emergence, 10 days after sowing, thinning was carried out, leaving four seedlings per pot. The variables evaluated were the following: emergency; emergency speed index; concentrations of chlorophyll $a, b$ and total; stem diameter at ground level; height and number of leaves 69 days after sowing. The increase in soil salinity from not saline (CEes $<2 d S \mathrm{~m}^{-1}$ ) to slightly saline ( $4 \mathrm{dS} \mathrm{m}^{-1}>$ CEes $\left.>2 \mathrm{dS} \mathrm{m}^{-1}\right)$ and moderately saline $\left(8 \mathrm{dS} \mathrm{m}^{-1}>\right.$ CEes $\left.>4 \mathrm{dS} \mathrm{m^{-1 }}\right)$ has stimulated the emergency, the initial growth and chlorophyll production in Parkinsonia aculeata plants, unlike what occurs with most of the species. This partially explains the success of their proliferation in certain sites in the caatinga.
\end{abstract}

Keywords: Caatinga; Biological invasion; Turkish.

\footnotetext{
${ }^{1}$ Recebido em 06.07.2012 aceito para publicação em 06.08.2013.

${ }^{2}$ Programa de Pós-Graduação em Agronomia da Universidade Federal da Paraíba, UfPB, Brasil. E-mail: <bezerra_ftc@yahoo.com.br>.

${ }^{3}$ Universidade Federal da Paraíba, UFPB, Brasil.E-mail: <landrade@cca.ufpb.br>, <lofeca@cca.ufpb.br $>$ e $<$ walterufpb@yahoo.com.br>.

${ }^{4}$ Programa de Pós-Graduação em Ciência do Solo da Universidade Federal da Paraíba, UFPB, Brasil. E-mail:

$<$ marlene_agro@hotmail.com>.
} 


\section{INTRODUÇÃO}

A Caatinga nordestina sensu lato é uma savana semiárida de clima tropical com chuvas de verão/outono e inverno sem chuvas, em sua maior parte. Composta por formações tropicais estacionais arbóreo-arbustivas, algumas delas com fisionomia de savana, este bioma apresenta temperatura elevada responsável pela acentuada evapotranspiração potencial (COUTINHO, 2006), caracterizando-se, principalmente, pela irregularidade espacial e temporal das precipitações pluviométricas. A Caatinga caracteriza-se também por possuir a vegetação mais heterogênea entre os biomas brasileiros (ARAÚJO; MARTINS, 1999) e se inserir entre os mais degradados pelo homem (MMA, 2002).

As áreas desmatadas na região tropical, conforme Buschbacher (1986), são abandonadas no período de cinco a 10 anos de uso, devido à degradação do solo, à invasão de erva daninha ou a mudanças nos incentivos econômicos. Nesse sentido, Sousa et al. (2007) constataram que um período de 10 a 15 anos após o cultivo de subsistência a regeneração da vegetação da Caatinga no Município de Assaré, CE, ainda estava ocorrendo. Adicionalmente à lenta recomposição vegetal, há também os riscos de salinização dos solos que, muitas vezes, inviabilizam as terras dos perímetros irrigados do semiárido (ACCIOLY, 2000), provocando perdas à agricultura e ao meio ambiente. Todas essas formas de degradação promovem o abandono de áreas antes produtivas. Devido à lenta regeneração natural, as áreas salinizadas podem permanecer desprovidas de vegetação por longos períodos ou ser invadidas por espécies mais adaptadas que, eventualmente, passam a causar outros problemas.

No Nordeste do Brasil, a irrigação foi intensificada a partir da década de 1970 e, por não ser, às vezes, adequadamente manejada, acaba provocando a degradação química e física do solo (VALLADARES; FARIA, 2004). É importante ressaltar também que os solos das regiões áridas e semiáridas, em geral, são mais férteis e, por isso, são potencialmente mais suscetíveis à salinidade e sodicidade pelos elevados teores de sais solúveis e de sódio trocável, associados às altas taxas de evapotranspiração e elevada irregularidade das chuvas.

As atividades antrópicas são as principais causas da degradação física, química e biológica dos solos que muito contribuem para o comprometimento da sustentabilidade econômica das atividades agrícolas e a qualidade do meio ambiente. Porém, fatores naturais também contribuem para a alteração dos padrões ecológicos e ambientais, entre os quais as invasões biológicas, que constituem a segunda causa mundial de perda da biodiversidade (ZILLER, 2001). Nesse contexto se insere a Caatinga nordestina, que está submetida às ameaças causadas pelos organismos alóctones, a exemplo de Prosopis juliflora (Sw.) DC. (ANDRADE et al., 2009; ANDRADE et al., 2010), Sesbania virgata (Cav.) Press. (SOUZA et al., 2011), Parkinsonia aculeata L. (FABRICANTE et al., 2009; FABRICANTE; FEITOSA, 2010; GONÇALVES et al., 2011), entre outras. A espécie Parkinsonia aculeata L. pertence à família Fabaceae e é vulgarmente conhecida por cina-cina, espinho-de-jerusalém, palo-verde e turco, entre outros (FABRICANTE; FEITOSA, 2010). Essa espécie apresenta porte arbustivo-arbóreo e é originária de zonas áridas, semiáridas e subúmidas compreendidas entre o Sul dos Estados Unidos da América do Norte e o Norte do Uruguai (HAWKINS et al., 2007). Para Fabricante e Feitosa (2010), apesar de a Parkinsonia aculeata possuir inúmeras potencialidades como biorremediação de solos contaminados, fixação de dunas no combate ao processo de desertificação, essência florestal em áreas com solos salinos, dendroenergética, madeireira, medicina popular, alimentação animal, apifauna, ornamental, entre outros, o que lhe ajudou na rápida dispersão é considerada em inúmeras regiões como planta invasora (MASUBELELE et al., 2009).

Na Região Nordeste do Brasil, essa espécie era exclusiva de alguns nichos, praticamente restritos às lagoas e áreas depressionárias, onde ocorria em pequeno número de espécimes. Contudo, nas últimas décadas tem-se registrado uma explosão das populações de Parkinsonia aculeata no entorno de açudes, nas matas ciliares e também em áreas de Caatinga típica, em populações de alta densidade (ANDRADE, 2006).

Entre as vantagens como produtos comerciais e os riscos pela invasão biológica de se explorar uma espécie vegetal, é muito importante conhecer seu comportamento para melhor avaliar os seus limites de tolerâncias aos fatores ambientais e os risco implícitos na introdução de um táxon. Pois a introdução de espécies exóticas invasoras pode perturbar o equilíbrio dos ecossistemas locais ou, mesmo, destruí-lo devido à ausência de concorrentes ou inimigos naturais, podendo empurrar para a extinção espécies nativas. 
Diante do exposto, este trabalho teve como objetivo avaliar os efeitos da salinidade na emergência e crescimento de plantas jovens de Parkinsonia aculeata $\mathrm{L}$.

\section{MATERIAL E MÉTODOS}

Este experimento foi desenvolvido no período de novembro de 2009 a março de 2010, em abrigo telado do Laboratório de Ecologia Vegetal do Departamento de Fitotecnia e Ciências Ambientais do Centro de Ciências Agrárias da Universidade Federal da Paraíba, em Areia, PB. As sementes de turco utilizadas no experimento foram coletadas em uma área monodominada pela espécie no Município de Gurinhém, Paraíba.

O substrato constou de material dos primeiros $20 \mathrm{~cm}$ de um Latossolo Vermelho- Amarelo de textura argiloarenosa, com os atributos químicos e físicos obtidos conforme metodologias sugeridas pela Embrapa (1997), contidos na Tabela 1.

Depois de passado em peneira com $8 \mathrm{~mm}$ de malha foram constituídos cinco grupos, que foram irrigados durante 20 dias, mantendo a umidade em nível da capacidade de campo, com água de condutividade elétrica: 0,2 (condutividade elétrica média da água de abastecimento); 1,5; 3,0; 4,5; e 6,0 dS m². Ao final dos 20 dias, depois de cada solo ser seco ao ar, foram determinados os valores da condutividade elétrica do extrato de saturação de cada grupo de substrato, obtendo-se as respectivas condutividades elétricas do extrato de saturação: 0,48; 2,12; 4,09; 6,03; e 7,96 dS m-1.

Após a salinização foram acondicionados $16 \mathrm{~kg}$ de cada substrato em vasos plásticos com capacidade para $21 \mathrm{l}$ e efetuada a semeadura de 10 sementes por vaso, na profundidade de $1,5 \mathrm{~cm}$. Previamente à semeadura, cada substrato foi umedecido para que houvesse acomodação das partículas.

Os tratamentos foram distribuídos em blocos casualizados com nove repetições e um vaso por parcela. A irrigação foi feita através do processo de pesagem com água de abastecimento, adicionando o nível de água evapotranspirada, de modo a manter cada substrato em nível da capacidade de campo.

Após a estabilização da emergência, realizou-se um desbaste, mantendo as quatro plântulas mais vigorosas por vaso. Com a estabilização ocorrida aos 10 dias após a semeadura, avaliou-se a emergência, considerando como emergidas as plântulas que possuíam as folhas cotiledonares livres do solo; índice de velocidade de emergência, obtida através de contagens diárias das plântulas emergidas entre o período da semeadura e a estabilização da emergência, conforme proposto por Maguire (1962).

Após a perda das folhas cotiledonares, 69 dias após a semeadura, duas plantas foram coletadas para determinação dos teores de clorofila a, b e total $(\mathrm{a}+\mathrm{b})$ nas folhas, conforme Aron (1949). Nas outras duas, mediu-se o diâmetro do caule no nível do solo com paquímetro digital; a altura, compreendida entre a distância do colo ao meristema apical da planta com régua graduada em milímetro; e contaram-se as folhas expandidas que tivessem pelo menos 50\% dos folíolos.

Os dados foram submetidos às análises de variância e de regressão. A condutividade elétrica do extrato de saturação do solo em função da condutividade elétrica da água de irrigação foi submetida à análise de regressão, com a significância pelo teste t, de Student, a 1\% de probabilidade.

Tabela 1 - Atributos químicos, quanto à Fertilidade, e físicos do solo utilizado no experimento.

Table 1 - Chemical traits regarding to fertility and physical traits of the soil used in the experiment.

\begin{tabular}{|c|c|c|c|c|c|c|c|c|c|c|}
\hline \multicolumn{11}{|c|}{ Atributos Químicos } \\
\hline $\begin{array}{l}\mathrm{pH} \\
\left(1: 2,5 \mathrm{H}_{2} \mathrm{O}\right)\end{array}$ & $\begin{array}{l}\text { CEes } \\
\text { dS } \mathrm{m}^{-1}\end{array}$ & $\mathrm{Ca}^{2+}$ & $\mathrm{Mg}^{2+}$ & $\begin{array}{c}\mathrm{Al}^{3+} \\
\mathrm{cmol} \\
\mathrm{c}\end{array}$ & $\mathrm{Na}^{+}$ & $\left(\mathrm{H}^{+}+\mathrm{Al}^{3+}\right)$ & SB & СТC & $\begin{array}{c}\mathrm{P}^{5+} \\
-\mathrm{mg} \mathrm{dm}^{-3}\end{array}$ & $\begin{array}{l}\text { M.O. } \\
\text { g kg-1 }^{-1}\end{array}$ \\
\hline 4,72 & 0,47 & 0,57 & 0,22 & 0,80 & 0,36 & 5,80 & 2,05 & 7,85 & 3,27 & 37,42 \\
\hline \multicolumn{11}{|c|}{ Atributos Físicos } \\
\hline Areia & & Argila & \multicolumn{4}{|c|}{$\begin{array}{l}\text { Densidade do solo } \\
-\mathrm{kg} \mathrm{dm}^{-3}\end{array}$} & \multicolumn{2}{|c|}{$\begin{array}{l}\text { Porosidade } \\
\mathrm{m}^{3} \mathrm{~m}^{-3}\end{array}$} & \multicolumn{2}{|c|}{ Classe textural } \\
\hline 498 & & 461 & 1,52 & & 2,63 & & \multicolumn{2}{|c|}{0,42} & \multicolumn{2}{|c|}{ Argilo arenosa } \\
\hline
\end{tabular}

Fonte: Próprio autor.

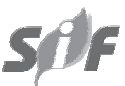

Revista Árvore, Viçosa-MG, v.37, n.4, p.611-618, 2013 


\section{RESULTADOS}

O aumento da salinidade da água elevou linearmente o caráter salino $(\mathrm{p} \leq 0,01)$ do extrato de saturação do substrato, no valor de $1,29 \mathrm{dS} \mathrm{m}^{-1}$, por incremento unitário da condutividade elétrica da água de irrigação (Figura 1). Após a umidade do substrato ter sido elevada ao valor da capacidade de campo, com as águas referentes a cada tratamento, constatou-se que a irrigação, durante os 20 dias de incubação, com 625 mL de água por quilo de substrato com condutividade elétrica de 0,$2 ; 1,5$; 3,$0 ; 4,5$; e $6,0 \mathrm{dS} \mathrm{m} \mathrm{m}^{-1}$, elevou a salinidade para 0,48 ;

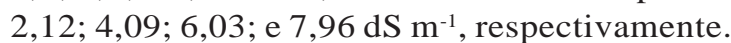

O aumento da salinidade das águas de irrigação não interferiu no processo de germinação das sementes, nem na produção de clorofila $b$ e clorofila total $(a+b)$, mas exerceu efeitos significativos ( $\leq 0,01)$ sobre as variáveis de crescimento e a produção de clorofila a das plantas de Parkinsonia aculeata, como indicado na Tabela 2.

A emergência e o índice de velocidade de emergência de plantas de Parkinsonia aculeata não foram afetados pelo aumento da salinidade do substrato, com médias de 91,5 e 1,93\%, respectivamente. Já as variáveis diâmetro do caule ao nível do solo, altura, número de folhas e concentrações das clorofilas a, b e total nas folhas de plantas de Parkinsonia aculeata, aos 69 dias após

Fonte: Próprio autor

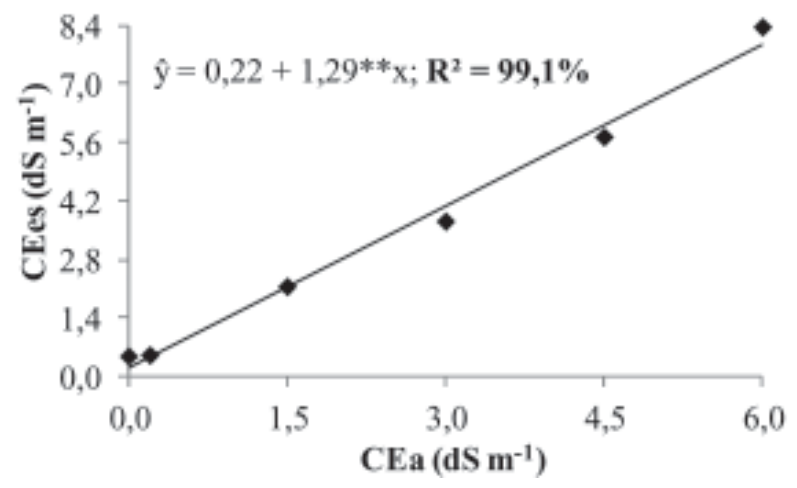

Figura 1 - Valores da condutividade elétrica do extrato de saturação do solo (CEes), em função da salinidade da água de irrigação (CEa). ** significativo a 1\% de probabilidade pelo teste t de Student.

Figure 1 - Values of the electrical conductivity of saturation extract of soil (CEes) according to salinity of irrigation water (electrical conductivity). ** Significant at $1 \%$ probability by Student's t test. a semeadura, em razão da condutividade elétrica do extrato de saturação do substrato, podem ser observadas na Figura 2A-D, respectivamente.

O aumento da salinidade no substrato provocado pelas irrigações estimulou significativamente o crescimento em diâmetro do caule das plantas até o valor de 3,1 mm e a condutividade elétrica máxima do extrato de saturação de 7,25 dS m ${ }^{-1}$ (Figura 2A). O aumento na salinidade do solo promoveu crescimento linear das plantas em altura, correspondente a $0,56 \mathrm{~cm}_{\text {planta }}{ }^{-1}$ para cada incremento unitário da condutividade elétrica do extrato de saturação do substrato (Figura 2B). A emissão foliar, assim como o crescimento em altura, aumentou linearmente em função da salinidade em nível de 0,62 folha planta ${ }^{-1}$ em cada aumento unitário da condutividade elétrica do extrato de saturação do solo (Figura 2C).

Como observado na altura e no número de folhas, as concentrações de clorofilas $a$ e clorofila total $(a+b)$ nas folhas das plantas também aumentaram em função da condutividade elétrica do extrato de saturação do substrato (Figura 2D). Estima-se um acréscimo de 0,06 e 0,036 $\mathrm{mg} \mathrm{L}^{-1}$ das clorofilas $a$ e clorofila total $(a+b)$, respectivamente, em folhas de Parkinsonia aculeata em cada aumento de $1 \mathrm{dS} \mathrm{m}^{-1}$ de condutividade elétrica do extrato de saturação do substrato. Quanto à clorofila $b$, as concentrações em folhas de Parkinsonia aculeata não se ajustaram aos modelos de regressões testados, tendo, em média, 2,82 $\mathrm{mg} \mathrm{L}^{-1}$.

\section{DISCUSSÃO}

A água de boa qualidade $\left(0,2 \mathrm{dS} \mathrm{m}^{-1}\right)$ não elevou significativamente o caráter salino do substrato, aumentando em apenas 2\% o valor inicial. Entretanto, incrementos marcadamente elevados de 351, 770, 1.283 e $1.594 \%$, em relação à condutividade elétrica de $0,47 \mathrm{dS} \mathrm{m}^{-1}$ que o substrato possuía antes da aplicação dos tratamentos, foram registrados em curto período de incubação do substrato (20 dias) com cada tipo de água.

Os fatores mais relacionados com a elevação da salinidade do solo da condição de não salino (CEes $\left.<2 \mathrm{dS} \mathrm{m}^{-1}\right)$, para ligeiramente salino $\left(4 \mathrm{dS} \mathrm{m}^{-1}>\right.$ CEes $\left.>2 \mathrm{dS} \mathrm{m}^{-1}\right)$ e moderadamente salino $\left(8 \mathrm{dS} \mathrm{m}^{-1}>\right.$ CEes $>4 \mathrm{dS} \mathrm{m}^{-1}$ ) são a salinidade das águas e a temperatura no interior do ambiente protegido. Durante as quatro horas mais quentes do dia a temperatura atingia valores 
Emergência e crescimento inicial de plantas de Parkinsonia...

Tabela 2 - Resumos das análises de variância e de regressão para a emergência (EMERG), índice de velocidade de emergência (IVE), diâmetro do caule ao nível do solo (DNS), altura (ALT), número de folhas (NF) e, concentrações de clorofila $\mathrm{a}\left(\mathrm{Cl}_{\mathrm{a}}\right), \mathrm{b}\left(\mathrm{Cl}_{\mathrm{b}}\right)$ e total $\left(\mathrm{Cl}_{\text {total }}\right)$ em folhas de Parkinsonia aculeata em função da condutividade saturação do substrato (CEes), Areia - PB, 2010.

Table 2 - Summary of analysis of variance and regression of emergence (EMERG), emergence speed index (IVE), stem diameter at ground level (DNS), height (ALT), number of leaves (NF) and, concentrations of chlorophyll a (Cla), $b(\mathrm{Clb})$ and total (Cltotal) in leaves of Parkinsonia aculeata according to conductivity of substrate saturation (CEes), Areia-PB, 2010.

\begin{tabular}{lcccccccc}
\hline Fonte de Variação & \multicolumn{7}{c}{ Quadrado Médio } \\
\hline & EMERG & IVE & DNS & ALT & NF & $\mathrm{Cl}_{\mathrm{a}}$ & $\mathrm{Cl}_{\mathrm{b}}$ & $\mathrm{Cl}_{\text {total }}$ \\
Bloco & 0,0243 & 0,0194 & 0,2757 & 17,0932 & 18,7375 & 0,0554 & 0,1132 & 0,2685 \\
CEes & $0,063^{\text {ns }}$ & $0,0506^{\text {ns }}$ & $1,0369^{* *}$ & $29,8696^{* *}$ & $42,8139^{* *}$ & $0,1222^{* *}$ & $0,0669^{\text {ns }}$ & $0,3248^{\text {ns }}$ \\
Resíduo & 0,0527 & 0,0706 & 0,077 & 6,125 & 5,7983 & 0,0292 & 0,1045 & 0,1529 \\
CV (\%) & 16,86 & 13,77 & 10,28 & 14,29 & 15,84 & 20,95 & 11,43 & 10,73 \\
Média & $91,56 \%$ & 1,93 & $2,7 \mathrm{~mm}$ & $17,32 \mathrm{~cm}$ & 15,2 folhas & $0,82 \mathrm{mg} \mathrm{L}^{-1}$ & $2,83 \mathrm{mg} \mathrm{L}^{-1}$ & $3,64 \mathrm{mg} \mathrm{L}^{-1}$ \\
\hline & & \multicolumn{7}{c}{ Teste de Regressão } \\
Linear & $0,1012^{\text {ns }}$ & $0,0465^{\text {ns }}$ & $3,5581^{* *}$ & $112,0018^{* *}$ & $141,8778^{* *}$ & $0,4385^{* *}$ & $0,1986^{\text {ns }}$ & $1,2272^{* *}$ \\
Quadrática & $0,0477^{\text {ns }}$ & $0,1059^{\text {ns }}$ & $0,5674^{*}$ & $2,835^{\text {ns }}$ & $16,7937^{\text {ns }}$ & $0,0023^{\text {ns }}$ & $0,0005^{\text {ns }}$ & $0,0006^{\text {ns }}$ \\
\hline
\end{tabular}

ns, * e **: não significativo e significativo a 5 e $1 \%$, respectivamente, pelo teste $\mathrm{F}$ de Snedecor.

Fonte: Próprio autor.

Fonte: Próprio autor
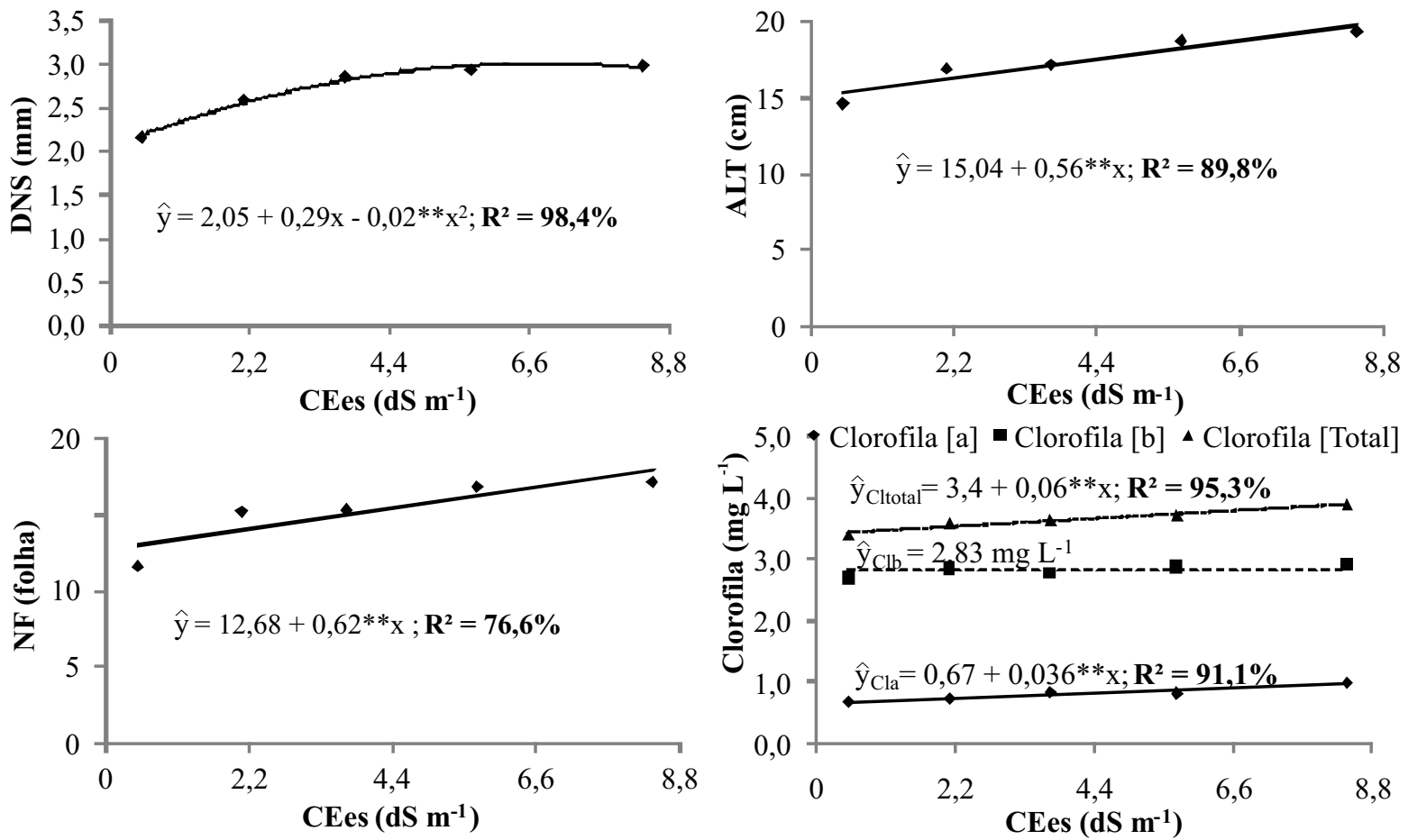

Figura 2 - Diâmetro do caule ao nível do solo (A), altura (B), número de folhas (C) e concentrações das clorofilas a, b e total nas folhas (D) de plantas de Parkinsonia aculeata, aos 69 dias após a semeadura em função da condutividade elétrica do extrato de saturação do substrato (CEes). ** significativo a 1\% de probabilidade pelo teste F de Snedecor.

Figure 2 - Stem diameter at the ground level (A), height (B), number of leaves (C) and concentration of the chlorophyll $a, b$ and total in the leaf (D) of Parkinsonia aculeate plants, 69 days after sowing according to the electrical conductivity of saturation extract of the substrate (CEes). ** Significant at 1\% probability by the Snedecor's F test. 
até acima de $40^{\circ} \mathrm{C}$, com superioridade de 10 a $12^{\circ} \mathrm{C}$ ao ambiente descoberto. Nessas condições, as irrigações adicionam sais ao solo em proporções crescentes com o teor salino das águas (CAVALCANTE et al., 2011) e a maior temperatura do ambiente promove maior evaporação e, com efeito, resulta em maior acúmulo de sais (LIMA et al., 2007; MEDEIROS et al., 2010). Além desses fatores, a textura do solo (GARCIA et al., 2008; QUEIROZ et al., 2009), a razão de adsorção de sódio da água (SILVA et al., 2007), entre outros, também elevam o nível de salinização dos solos.

Verifica-se que o elevado teor salino do substrato acima de $7 \mathrm{dS} \mathrm{m}$ m $^{-1}$ não comprometeu a emergência, o índice de emergência nem a produção de clorofila $b$ nas folhas da Parkinsonia, podendo evidenciar que o limite de tolerância à ação da salinidade da espécie durante a germinação e o crescimento inicial é superior $7 \mathrm{dS} \mathrm{m} \mathrm{m}^{-1} \mathrm{e}$, conforme Ayers e Westcot (1999), está entre as plantas tolerantes aos efeitos dos sais. Os dados de Agra (2010) corroboram essas informações, pois se observou que o aumento no teor salino do substrato de até $6 \mathrm{dS} \mathrm{m}^{-1}$ não interferiu na germinação nem no índice de velocidade de germinação de sementes de Parkinsonia aculeata.

Nessas condições, a elevação das concentrações de sais na solução do solo, que diminui o potencial osmótico e prejudica a disponibilidade e absorção de água à maioria das plantas cultivadas (TESTER; DAVENPORT, 2003), não foi suficiente para inibir o crescimento do eixo embrionário nem o crescimento inicial das plantas. Plantas nativas do semiárido, como Zizyphus joazeiro Mart. (Rhamnaceae) (LIMA; TORRES, 2009) e Mimosa caesalpiniifolia Benth. (MOURA et al., 2011), possuem baixa tolerância à salinidade dos solos, com redução significativa do poder germinativo em substratos com potencial osmóticos a partir de 0,3 $\mathrm{MPa}\left(0,75 \mathrm{dS} \mathrm{m}^{-1}\right)$ e -0,5 $\mathrm{MPa}\left(1,25 \mathrm{dS} \mathrm{m}^{-1}\right)$, respectivamente. Tal fato evidencia que mesmo algumas das plantas adaptadas às condições do Nordeste brasileiro não são adaptadas às condições de elevada concentração de sais.

Apesar de a tendência do crescimento em diâmetro das plantas de Parkinsonia aculeata com o aumento da salinidade do solo estar compatível com a ausência de efeitos do mesmo nível de salinidade na fase de emergência e crescimento inicial das plantas, a partir de 7,25 dS m-1 o aumento da salinidade do solo inibiu o desenvolvimento caulinar de Parkinsonia aculeata. Dessa forma, o nível de tolerância foi inferior ao registrado por Holanda et al. (2007), ao concluírem que o teor salino do solo de até $40,8 \mathrm{dS} \mathrm{m}^{-1}$ não exerceu efeitos significativos no crescimento inicial dessa mesma espécie.

As alturas nos substratos de maior salinidade superam os 16,3 e 15,5; 16,6; e 15,3 cm em plantas de Parkinsonia aculeata irrigadas com água de boa qualidade e desenvolvidas em ambiente sombreado e em pleno sol nos recipientes sacos de polietileno e tubetes até 35 dias após a semeadura (FARIAS JÚNIOR et al., 2007). Na condição ambiental que os dados foram obtidos, verifica-se que o aumento da salinidade estimulou o crescimento das plantas. Hussain e Alshammary (2008) constataram que o aumento da salinidade do solo inibiu o crescimento de Parkinsonia aculeata, resultando no menor valor do nível salino de 19,3 dS m¹ . Já Holanda et al. (2007) não observaram diferença na altura de Parkinsonia aculeata cultivada em substrato não salino e salino com 40,8 dS me condutividade elétrica do extrato de saturação.

Nas condições em que o trabalho foi realizado, o aumento da salinidade que estimulou o crescimento das plantas pelo diâmetro caulinar, em altura e número de folhas, resultou também em maior área foliar e, com efeito, em maior capacidade das plantas mais tolerantes em se ajustarem osmoticamente a ambientes adversamente salinos (KATERJI et al., 2000).

O excesso de sais dissolvidos na solução do solo, além dos problemas de salinidade e toxicidade, limita a absorção de água e nutrientes e provoca danos celulares e moleculares à maioria das plantas glicófílas (TAIZ; ZEIGER, 2009; DIAS; BLANCO, 2010). Porém, não compromete o crescimento vegetativo nem as concentrações de clorofilas em folhas de Parkinsonia aculeata até os 69 dias após a emergência das plantas. O estresse pode afetar o estabelecimento de plantas alóctones por duas vias, ou seja, as espécies não nativas não poderiam tolerar os níveis máximos de estresse no hábitat ou ocorrerão mudanças no equilíbrio competitivo entre invasores e nativos (ALPERT et al., 2000).

\section{CONCLUSÕES}

Na fase juvenil, indivíduos de Parkinsonia aculeata têm o crescimento e concentração de clorofila estimulados pela salinidade do solo. 
Durante os primeiros 69 dias após a emergência, indivíduos de Parkinsonia aculeata apresentam tolerância à salinidade do solo, o que mostra que essa espécie possui mais uma habilidade competitiva, que a habilita para invadir determinados sítios do semiárido.

A espécie Parkinsonia aculeata deve ser monitorada de forma mais cuidadosa, devido ao fato de possuir vantagens adaptativas a ambientes salinos e à sua forma agressiva de ocupar diversos nichos.

\section{REFERÊNCIAS}

ACCIOLY L. J. O. Degradação do solo e desertificação no Nordeste do Brasil. Boletim Informativo Sociedade Brasileira de Ciência do Solo, v.25, n.1, p.23-25, 2000.

AGRA, P. F. M. Invasão biológica por Parkinsonia aculeata L. (Fabaceae) no semiárido paraibano: uma abordagem voltada para ecofisiologia de sementes. 2010. 73f. Dissertação (Mestrado em Agronomia) Universidade Federal da Paraíba, Areia, 2010.

ALPERT, P.; BONE, E.; HOLZAPFEL, C. Invasiveness, invasibility and the role of environmental stress in the spread of non-native plants. Urban \& Fischer Verlag, v.3, n.1, p.52-66, 2000.

ANDRADE, L. A. Espécies exóticas invasora no nordeste do Brasil: impactos nos ecossistemas locais. In: MARIATH, J. E. A.; SANTOS, R. P. (Ed.). Os avanços da botânica no inicio do século XXI: morfologia, fisiologia, taxonomia, ecologia e genética. Porto Alegre: Sociedade Botânica do Brasil, 2006. p. 524-528.

ANDRADE, L. A.; FABRICANTE, J. R.; OLIVEIRA, F. X. Impactos da invasão de Prosopis juliflora (Sw.) DC. (Fabaceae) sobre o estrato arbustivo-arbóreo em áreas de Caatinga no Estado da Paraíba, Brasil. Acta Scientiarum, v.32, n.3, p.249-255, 2010.

ANDRADE, L. A.; FABRICANTE, J. R.; OLIVEIRA, F. X. Invasão biológica por Prosopis juliflora (Sw.) DC.: impactos sobre a diversidade e a estrutura do componente arbustivo-arbóreo da caatinga no estado do Rio Grande do Norte, Brasil. Acta Botânica Brasílica, v.23, n.4, p.935-943, 2009.
ARAÚJO, F. S.; MARTINS, F. R. Fisionomia e organização da vegetação do carrasco no planalto da Ibiapaba, Estado do Ceará. Acta Botânica Brasilica, v.13, n.1, p.1-13, 1999.

ARNON, D. I. Copper enzymes in isolated chloroplasts polyphenol oxidase in Beta vulgaris. Plant Physiology, v.24, n.1, p.1-15, 1949.

AYERS, R. S.; WESTCOT, D. W. A qualidade da água na agricultura. Campina Grande: UFPB, 1991. 218p. (Estudos FAO Irrigação e Drenagem, 29).

BUSCHBACHER, R. J. Tropical deforestation and pasture development. BioScience, v.1, n.36, p.22-28, 1986.

CAVALCANTE, L. F. et al. Irrigação com águas salinas e uso de biofertilizante bovino na formação de mudas de pinhão-manso. Irriga, v.16, n.3, p.288-300, 2011.

COUTinho, L. M. O conceito de bioma. Acta Botânica Brasilica, v.20, n.1, p.13-23, 2006.

DIAS, N. S.; BLANCO, F. F. Efeitos dos sais no solo e na planta. In: GHEYI, H. R.; DIAS, N. S.; LACERDA, C. F. (Ed.). Manejo da salinidade na agricultura: estudos básicos e aplicados. Fortaleza: Instituto Nacional de Ciência e Tecnologia em Salinidade, 2010. p.127-141.

EMPRESA BRASILEIRA DE PESQUISA AGROPECUÁRIA - EMBRAPA. Centro Nacional de Pesquisa do Solo. Manual de métodos de análises do solo. 2.ed. Rio de Janeiro: 1997. 212p.

FABRICANTE, J. R. et al. Respostas da Parkinsonia aculeata L. ao corte e queima em área invadida no agreste paraibano Revista Brasileira de Ciências Agrárias, v.4, n.3, p.293-297, 2009.

FABRICANTE, J. R.; FEITOSA, S. S. Parkinsonia aculeata L. Agropecuária Científica no Semi-Árido, v.6, n.2, p.1-13, 2010.

FARIAS JÚNIOR, J. A. et al. Crescimento inicial de mudas de turco sob diferentes tipos de recipientes e níveis de luminosidade. Revista Brasileira de Ciências Agrárias, v.2, n.3, p.228-232, 2007.

Revista Árvore, Viçosa-MG, v.37, n.4, p.611-618, 2013 
GONÇALVES, G. S. et al. Estudo do banco de sementes do solo em uma área de caatinga invadida por Parkinsonia aculeata L. Revista Brasileira de Biociência, v.9, n.4, p.428436, 2011.

GARCIA, G. O. et al. Alterações químicas de dois solos irrigados com água salina. Revista

Ciência Agronômica, v.39, n.1, p.7-18, 2008.

HAWKINS, J. A. et al. Intercontinental dispersal prior to human translocation revealed in a cryptogenic invasive tree. New Phytologist, v.175, n.3, p.575-587, 2007.

HOLANDA, A. C. et al. Desenvolvimento inicial de espécies arbóreas em ambientes degradados por sais. Revista de Biologia e Ciências da Terra, v.7, n.1, p.39-50, 2007.

HUSSAIN, G.; ALSHAMMARY, S. F. Effect of water salinity on survival and growth of landscape trees in Saudi Arabia. Arid Land Research and Management, v.22, p.320-333, 2008.

KATERJI, N. et al. Salt tolerance classification of crops according to soil salinity and to water stress day index. Agricultural Water Management, v.43, n.1, p.37-66, 2000.

LIMA, B. G.; TORRES, S. B. Estresses hídrico e salino na germinação de sementes de Zizyphus joazeiro Mart. (Rhamnaceae). Revista Caatinga, v.22, n.4, p.93-99, 2009.

LIMA, C. B. et al. Influência da água salina nas características físico-químicas do solo e no desenvolvimento da mamoneira cultivada em vasos. Revista Caatinga, v.20, n.4, p.132-136, 2007.

MAGUIRE, J. D. Speed of germination-aid in selection and evaluation for seedlig emergence and vigor. Crop Science, v.2, n.1, p.176-177, 1962.

MASUBELELE, M. L.; FOXCROFT, L. C.; MILTON, S. J. Alien plant species list and distribution for Camdeboo National Park, Eastern Cape Province, South Africa. Koedoe, v.51, n.1, p.80-89, 2009.

Revista Árvore, Viçosa-MG, v.37, n.4, p.611-618, 2013
MEDEIROS, P. R. F.; SILVA, E. F. F.; DUARTE, S. N. Salinidade em ambiente protegido. In: GHEYI, H. R.; LACERDA, C. F.; DIAS, N. S. (Ed.). Manejo da salinidade na agricultura: estudos básicos e aplicados. Fortaleza: INCTSal, 2010. p.83-92.

BRASIL. - Ministério do Meio Ambiente. Avaliação e ações prioritárias para a conservação da biodiversidade da caatinga. Brasília: 2002. 40p.

MOURA, M. R. et al. Efeito do estresse hídrico e do cloreto de sódio na germinação de Mimosa caesalpiniifolia Benth. Revista Verde, v.6, n.2, p.230-235, 2011.

QUEIROZ, S. O. P.; TESTEZLAF, R.; MATSURA, E. E. Metodologia para avaliação da salinidade do solo em ambiente protegido. Irriga, v.14, n.3, p.383-397, 2009.

SILVA, M. O. et al. Risco de salinização em quatro solos do Rio Grande do Norte sob irrigação com águas salinas. Revista Brasileira de Ciência Agrária, v.2, n.1, p.8-14, 2007.

SOUSA, J. R.; MENDES, P. G. A.; SOUZA, M. M. A. Regeneração da vegetação de caatinga após cultivo de subsistência em Assaré-CE. Revista Brasileira de Biociências, v.5, n.1, p.192-194, 2007.

SOUZA, V. C. et al. Avaliação populacional de Sesbania virgata (Cav.) Pers. (Fabaceae Lindl.), nas margens do rio Paraíba. Revista

Brasileira de Ciência Agrária, v.6, n.2, p.314-320, 2011.

TAIZ, L.; ZEIGER, E. Fisiologia vegetal. 4.ed. Porto Alegre: Artmed, 2009. 848p.

TESTER, M.; DAVENPORT, R. Na ${ }^{+}$tolerance and $\mathrm{Na}^{+}$transport in higher plants. Annals of Botany, v.91, p.503-527, 2003.

VALLADARES, G. S.; FARIA, A. L. L. SIG na Análise do risco de salinização na bacia do Rio Coruripe, AL. Engevista, v.6, n.3, p.86-98, 2004.

Substituir por: ZILLER, S. R. Plantas exóticas invasoras: a ameaça da contaminação biológica. Revista Ciência Hoje, v.30, n. 178, p. 77-79, 2001. 